\title{
The Predictors of High Dietary Salt Intake among Hypertensive Patients in Iran
}

\author{
Parvin Reyhani, ${ }^{1}$ Fariba Azabdaftari, ${ }^{2}$ Mehrangiz Ebrahimi-Mamagani, ${ }^{3,4}$ \\ Mohammad Asghari-Jafarabadi, ${ }^{5,6}$ and Behjat Shokrvash $\mathbb{D}^{1,7}$ \\ ${ }^{1}$ Department of Health Education and Promotion, Faculty of Health, Tabriz University of Medical Sciences, Tabriz, Iran \\ ${ }^{2}$ Basic Sciences Department, Paramedical School, Tabriz University of Medical Sciences, University Campus, Danshgah Street, \\ Tabriz, Iran \\ ${ }^{3}$ Social Determinant of Health Research Center, Tabriz University of Medical Sciences, Tabriz, Iran \\ ${ }^{4}$ Department of Biochemistry and Diet Therapy, School of Nutrition and Food Sciences, Tabriz University of Medical Sciences, \\ Tabriz, Iran \\ ${ }^{5}$ Road Trafic Injury Research Center, Tabriz University of Medical Sciences, Tabriz, Iran \\ ${ }^{6}$ Department of Statistics and Epidemiology, Faculty of Health, Tabriz University of Medical Sciences, Tabriz, Iran \\ ${ }^{7}$ Medical Education Research Center, Health Management and Safety Promotion Research Institute, \\ Tabriz University of Medical Sciences, Tabriz, Iran
}

Correspondence should be addressed to Behjat Shokrvash; shokrvash@tbzmed.ac.ir

Received 23 July 2019; Revised 3 February 2020; Accepted 20 March 2020; Published 8 April 2020

Academic Editor: Salvatore Corrao

Copyright (c) 2020 Parvin Reyhani et al. This is an open access article distributed under the Creative Commons Attribution License, which permits unrestricted use, distribution, and reproduction in any medium, provided the original work is properly cited.

Background. Hypertension and its complications are among the major health problems all over the world, particularly in developing countries. The aims of this study were to show that, weather the hypertensive patients follow the expertise recommendations and differences between men and women in their levels of knowledge and behavior in salt taking. Methods. The present cross-sectional study was conducted among all hypertensive patients in rural health centers of Tabriz, Iran, in Feb-May; 2016. Data were collected by an interviewer-administrated questionnaire, along with anthropometric, blood pressure, and 24-hour urinary sodium excretion measurements. Multivariate logistic regression analysis was used to compute adjusted odds ratio (OR). Results. In all 205 patients, $62.9 \%$ female, $40.5 \%$ aged over 60 years, and $53.7 \%$ with low or moderate socioeconomic status, $49.3 \%$ body mass index (BMI) $30 \mathrm{~kg} / \mathrm{m}^{2}$ and above, $10.2 \%$ of the patients had systolic/diastolic equal and above $(\geq) 40 / 90 \mathrm{mmHg}$, participated in the study. In total, $16.6 \%$ were aware of the daily salt allowance for healthy people with sex difference $(P<0.001)$. Significant predictors of adding salt beyond the dietary recommendations in food preparation were occupation (unemployed) $(\mathrm{OR}=4.05,95 \% \mathrm{CI}=1.041-15.78, \quad(P=0.044))$ and blood pressure level (systolic/diastolic $\geq 140 / 90)(\mathrm{OR}=2.76,95 \%$ $\mathrm{CI}=1.28-5.96(P=0.010))$, while adding salt at the table correlated with sex $(\mathrm{men})(\mathrm{OR}=4.47,95 \% \mathrm{CI}=1.21-16.57(P=0.025))$, age (54-59) $(\mathrm{OR}=0.0595 \% \mathrm{CI}=0.01-0.39,(P=0.005))$, and knowledge (general) $(\mathrm{OR}=1.06,95 \% \mathrm{CI}=0.99-1.13(P=0.05))$. Conclusion. The different pattern of salt intake was observed between men and women. In general, the amount of salt taken by hypertensive patients is higher than recommended allowances. Both men and women add extra amount of salt to food, women when preparing food and men at the table. Salt intake level both during preparing and eating food may be associated with occupation (unemployed), blood pressure level (systolic/diastolic $\geq 140 / 90$ ), sex (men), age (54-59), and also patient knowledge (general). 


\section{Introduction}

Hypertension and its complications are among the major health problems in many societies particularly, developing ones [1-3]. Different studies are indicative of high-salt intake among patients with hypertension [4-6]. A 30\% reduction in salt intake is an international and a national goal to prevent and to control noncommunicable diseases, by the year 2020 $[7,8]$.

As one of the major risk factors of mortality, hypertension is considered as a leading factor for about $13 \%$ of the deaths in the world and also accounts for $12.1 \%$ of deaths in low- and moderate-income countries. In the Eastern Mediterranean region, hypertension alone accounts for $26 \%$ of deaths, while the other complications such as cardiovascular diseases and stroke, combined, lead to $31 \%$ of deaths $[2,3]$.

Excessive salt (sodium) intake is not only responsible for hypertension, cardiovascular diseases, and strokes but also associated directly with other diseases such as osteoporosis, nephrolithiasis, and gastric cancer $[9,10]$. Therefore, control of salt intake is considered as a crucial element for a healthy and highly-qualified life $[4,11,12]$. It is believed that consuming high-fiber diets combined with reduced salt intake can play a critical role in prevention of hypertension and its fatal cardiovascular complications, as well as decreasing medical costs [13-17].

However, adding salt as a flavor to food is actually a cultural, psychological, habitual, and in turn behavioral matter $[6,18]$. It happens in two phases: preparing food and eating at the table. Results of studies have illustrated multiple determinants regarding the addition of salt when preparing food or at the table $[6,19]$. In most societies, people are not usually aware of the naturally occurring salt in nutrients, such as bread, milk, meat, and also other manufactured products $[13,20]$. Thus, they add salt to the foods which already contain sufficient amount of salt.

In a sample of urban population in Iran, salt (sodium) intake has been reported $9.6-11.1 \mathrm{~g} /$ day and $2-10.3 \mathrm{~g} / \mathrm{day}$ based on urinary sodium excretion and salt intake investigations, respectively [21-24]. The amount is high compared to the World Health Organization (WHO) recommendations of daily salt intake for healthy individuals ( $<5 \mathrm{~g}$ salt, equivalent to $2 \mathrm{gr}$ sodium) and patients with hypertension ( $<4 \mathrm{~g}$ salt, equivalent to $1.5 \mathrm{gr}$ sodium) $[25,26]$.

In Tehran (Iran), the blood pressure of $60 \%$ of hypertensive patients was not controlled, even though these patients were aware of their disease. However, the attitude of the patients who knew they were hypertensive was a predictive factor in salt intake [22]. Among the highly predictive of the sodium intake factors is patient knowledge of nutrients containing salt as well as their perception of illness [27]. The aims of this study were to investigate that (1) what are the predictors of salt intake among patients? (2) Do the patients diagnosed as hypertensive follow the expertise recommendations in salt taking? (3) Are there any differences between men and women in their levels of knowledge and behavior in salt taking?

\section{Materials and Methods}

2.1. Participants. This was a cross-sectional study conducted among a total number of 205 patients diagnosed with hypertension during the last six months, before the time of the study, and were under the coverage of 12 rural health centers of Tabriz city, Iran in Feb-May 2016. The subjects were selected based on the inclusion criteria of the aim of the study (diagnosed hypertensive and with no coexisting disease(s) and complications during the last six months, covered by the rural health centers in Tabriz and agreed to participate in the study). The patients sent written invitations to participate in the investigation and attended the health center for data collection, after the approval of number P/ 326/Oct. 2016. As most of the patients were illiterate, data collection was done by interviewing the patients and filling the questionnaires by interviewers.

2.2. Data Collection. There was a multisectional questionnaire, including anthropometric indices. Blood pressure and the amount of urine sodium and creatinine ( $\mathrm{mmol} /$ day) were taken.

Demographic data consisted of questions regarding patient's age, sex, education level, occupation, household size, and socioeconomic status. Socioeconomic status was determined by the valid family affluence scale based on existence or nonexistence of ordinary household items, scoring from 0 to 1 and above [28]. Summing up of scores was categorized under 2 groups: low and moderate (0-14) and high (15-23).

2.3. Knowledge, Attitude, and Behavior. Knowledge, attitude, and behavior of patients were assessed based on the valid questionnaire [29, 30]. Four questions: (1) the patients' awareness on salt allowance and recommended for healthy people, (2) the patients' awareness on salt allowance and recommended for hypertensive people, (3) diseases induced by salt intake, and (4) the list of the common high-salt foods (23 items) were included in the knowledge questionnaire. Three questions were scored and rated based on correct and incorrect answers; 23 questions taken from a list of common high-salt foods were scored and rated based on correct (too much, much, and moderate), incorrect (too little, far too little, and do not know). To analyse the data, the replies differentiated based on "correct" and "incorrect" following a two-point scale: 1 point for "know or correct answer," and 0 points for "don't know or incorrect answer"; the knowledge scores were computed by summing over the items and ranged from 0 to 26 . The data related to patient general knowledge entered into the logistic regression model as a continuous variable.

To identify the differences between men and women, knowledge was also analyzed specifically; patient knowledge on disease related to high-salt intake and on appropriate amount of recommended salt intake for healthy and unhealthy people.

Attitude was assessed using five questions: (1) preference of food taste (salty or not salty), (2) the questions related to 
the healthfulness of low-salt food for healthy people, (3) the questions related to the healthfulness of low-salt food for patients, (4) in general, low-salt food is healthier, and (5) salty food is more delicious. The questions were scored based on a five point scale (strongly agree: 5 , agree: 4 , undecided: 3 , disagree: 2 , and strongly disagree: 1 ); the scores for attitude was computed by summing over the items for attitude which ranged from 5 to 25 .

Two questions were asked to assess the patients' behavior on adding salt to food: (1) adding salt when preparing food and (2) adding salt at the table. The amount of salt added when preparing food or at the table was estimated based on home scales that was one teaspoon ( $1 \mathrm{tsp}$ ) equivalent to 4 grams. The possible answers included $\geq 3$ tsps, 2 tsps, 1 tsp, 0.5 tsp, or not at all. For analysis of healthy and unhealthy behaviors, the scores of 0 and 1 were used, respectively.

2.4. Anthropometric Indices. Height (centimeter) and weight (kilogram) of the patients were measured by an adults scale to calculate body mass index (BMI), weight $(\mathrm{kg})$ divided by height squared $\left(\mathrm{m}^{2}\right)$ [31]. A trained public health technician measured systolic and diastolic blood pressure $(\mathrm{mmHg})$ of all the patients who were diagnosed as hypertensive during the last six months and were taking medication, and the results were recorded and categorized according to normative (140/90), borderline, systolic $\leq 140$, and diastolic $>90$, systolic $>140$, and diastolic $\leq 90$, and hypertensive (equal and above 140/90). A mercury manometer was used to measure the blood pressure in sitting position.

Sodium and creatinine ( $\mathrm{mmol} /$ day) were measured in a random urine sample on the day of data collection. The urine samples were assayed in the cooperating laboratory, by caretium were made in Hong Kong.

2.5. Assessment of Food Intake. A validated semiquantitative food frequency questionnaire (FFQ) was used to obtain data on consumption of high-salt food among patients [32, 33]. The FFQ consisted of 148 food items categorized in 39 food groups.

Sodium and creatinine ( $\mathrm{mmol} /$ day) were measured in a random urine sample on the day of data collection. The urine samples were assayed in the cooperating laboratory by caretium made in Hong Kong.

2.6. Statistical Analyses. Data were analyzed using SPSS software 22.0 (SPSS Inc., Chicago, IL, USA). Data were summarized using frequency (percent) for categorical variables and mean and standard deviation (SD) for numerical variables. To assess differences between groups chi-squared test, Fisher's exact test, and independent samples $t$-test were used. The association between the behavior of adding salt when preparing food and also during eating food and the variables such as age, socioeconomic status, knowledge, attitude, and BMI were assessed by logistic regression modeling. Proper behavior, adding salt less than or equal to $1 \mathrm{tsp}$, was scored as 0 ; and the behavior of too much salt addition, more than 1tsp, was scored as 1 [34].
2.7. Ethical Considerations. The aims and the significance of the study were fully explained to the participants. The participants were also assured that their information would be kept confidential. Then, those willing to participate in the study signed a consent form to enter the study. Those who refused to give the urine sample, emigrants, pregnant women, having the history of psychological disorders, and suffering from metabolic diseases, renal failure, diabetes or secondary hypertension, were excluded from the study. This study was registered under the ethics code; IR.TBZMED.REC.1395.792.

\section{Results}

3.1. Patient's Characteristics. Out of 205 participant hypertensive patients, $62.9 \%$ were women, $91.3 \%$ illiterate or low literate, and $53.7 \%$ belonged to the low and middle socioeconomic status. There was a significant difference between men and women according to age, occupation $(P<0.001)$, BMI $(P=0.017)$, and blood pressure $(P<0.001)$ (Table 1$)$.

\subsection{Patient's Sodium Intake and Blood Pressure. The mean} (SD) of sodium intake among the patients was 4049.0 (2825.0) mg. More than half of the patients $57.1 \%$ had daily $3000 \mathrm{mg}$ salt intake. Sodium intake greater than $3000 \mathrm{mg}$ was observed in $58.2 \%$ of all patients and $63.4 \%$ of women with blood pressure lower than 140/90 mmHg. Among those with blood pressure $\geq 140 / 90 \mathrm{mmHg}, 57.1 \%$ all patients had sodium intake over $3000 \mathrm{mg}$, without significant differences between men and women $(P=0.929)$ (Table 2$)$.

3.3. Patient's Knowledge, Attitude, and Behaviors. Distribution of frequency and percent of general knowledge and specific knowledge on disease related to high-salt intake were not significant $(P=0.995, P=0.999)$ based on sex (Table 3). There was a significant difference between men and women according to knowledge $(P=0.023)$ and behavior of adding salt during eating $(P<0.001)$ (Table 3$)$. Patient knowledge on diseases related to high-salt intake showed significant $(P<0.001)$ based on participant blood pressure level (Table 4).

The analyses indicate that the knowledge of the participants on appropriate amount of recommended salt intake for healthy people was significant based on sex. However, the knowledge on appropriate amount of recommended salt intake for unhealthy people was significant based on hypertension levels of the patients $(P<0.001)$ (Table 5).

About half of the patients $44.9 \%$ (48.7\% men and $42.6 \%$ women) added no or only 1 tsp salt when preparing food; no significant sex difference was observed $(P=0.243)$. More than half of the patients $59.5 \%$ (40.8\% men and $70.5 \%$ women) added 1tsp of salt at the table with a significant difference between men and women $(P<0.001)$ (Table 2).

3.4. Predictors of Patient Salt Intake. Results of the logistic regression test adjusted for the variables: sex, age, education level, occupation, socioeconomic status, blood pressure levels, BMI, knowledge, and attitude revealed that the adding salt beyond the 
TABle 1: Patients' characteristics.

\begin{tabular}{|c|c|c|c|c|}
\hline & $\begin{array}{c}\text { All } \\
N=205\end{array}$ & $\begin{array}{c}\text { Women } \\
129(62.9)\end{array}$ & $\begin{array}{c}\text { Men } \\
76(37.1)\end{array}$ & $P$ \\
\hline Age (year) & & & & $0.001^{\mathrm{a}}$ \\
\hline Under 33 & $8(3.9)^{c}$ & $5(9.0)^{\mathrm{c}}$ & $3(3.9)^{\mathrm{c}}$ & \\
\hline $34-43$ & $19(9.3)$ & $18(14.0)$ & $1(1.3)$ & \\
\hline $44-53$ & $61(29.8)$ & $44(34.1)$ & $17(22.4)$ & \\
\hline $54-59$ & $34(16.6)$ & $22(17.1)$ & $12(15.8)$ & \\
\hline 60 and above & $83(40.5)$ & $40(31)$ & $43(56.6)$ & \\
\hline $\mathrm{M}(\mathrm{SD})^{\mathrm{e}}$ & $56.34(12.88)$ & $53.2(11.47)$ & $61.63(13.18)$ & \\
\hline Education level (year) & & & & $0.190^{\mathrm{b}}$ \\
\hline 0 & $118(57.6)$ & $77(59.7)$ & $41(53.9)$ & \\
\hline $1-6$ & $69(33.7)$ & $41(31.8)$ & $28(36.8)$ & \\
\hline 7 and above & $18(8.8)$ & $11(8.5)$ & $7(9.2)$ & \\
\hline $\mathrm{M}(\mathrm{SD})^{\mathrm{e}}$ & $2.20(3.06)$ & $1.98(3.02)$ & $2.57(3.13)$ & \\
\hline Occupation & & & & $<0.001^{\mathrm{d}}$ \\
\hline Employed & $77(37.6)$ & $7(5.4)$ & $70(92.1)$ & \\
\hline Unemployed & $128(62.4)$ & $122(94.6)$ & $6(7.9)$ & \\
\hline FAS (item) $)^{\mathrm{f}}$ & & & & $0.41^{\mathrm{d}}$ \\
\hline High level (15-23) & $95(46.3)$ & $61(64.2)$ & $34(35.8)$ & \\
\hline Low/moderate level (0-14) & $110(53.7)$ & $68(61.8)$ & $42(38.2)$ & \\
\hline BMI $\left(\mathrm{kg} / \mathrm{m}^{2}\right)^{\mathrm{g}}$ & & & & $0.017^{\mathrm{b}}$ \\
\hline Underweight (18.51-25.00) & $25(12.2)^{\mathrm{a}}$ & $10(7.8)^{\mathrm{a}}$ & $15(19.7)^{\mathrm{a}}$ & \\
\hline Normal weight $(25.01-30.00)$ & $79(38.5)$ & $48(37.2)$ & $31(40.8)$ & \\
\hline Overweight and obesity (30.01 and above) & $101(49.3)$ & $71(55.0)$ & $30(39.5)$ & \\
\hline Blood pressure level (systolic/diastolic) & & & & $0.001^{\mathrm{c}}$ \\
\hline Normotensive (under 140/90) & $141(68.8)$ & $101(78.3)$ & $40(52.6)$ & \\
\hline Borderline $^{\mathrm{d}}$ & $43(21)$ & $19(14.7)$ & $24(31.6)$ & \\
\hline Hypertensive (over 140/90) & $21(10.2)$ & $9(7.0)$ & $12(15.8)$ & \\
\hline
\end{tabular}

TAвLE 2: Distribution of frequency and percentage of patient blood pressure based on sex sodium intake.

\begin{tabular}{|c|c|c|c|c|c|c|c|c|c|}
\hline \multirow[b]{2}{*}{ Sodium intake ${ }^{\mathrm{a}}$} & \multicolumn{3}{|c|}{ All $N=205$} & \multicolumn{3}{|c|}{ Women 129(62.9) } & \multicolumn{3}{|c|}{ Men 76(37.1) } \\
\hline & $<2000$ & $2000-3000$ & $>3000$ & $<2000$ & $2000-3000$ & $>3000$ & $<2000$ & $2000-3000$ & $>3000$ \\
\hline Normotensive $(<140 / 90)$ & $26(18.4)$ & $33(23.4)$ & $82(58.2)$ & 15 (14.9) & $22(21.8)$ & $64(63.4)$ & $11(27.5)$ & $11(27.5)$ & $18(45.0)$ \\
\hline Borderline $^{c}$ & $7(16.3)$ & $13(30.2)$ & $23(5.53)$ & $0(0.0)$ & $5(26.3)$ & $14(7.73)$ & $7(29.2)$ & $8(33.3)$ & $9(5.37)$ \\
\hline $\begin{array}{l}\text { Hypertensive }(\geq 140 / 90) \\
P\end{array}$ & $\begin{array}{l}4(19.0) \\
0.929^{\mathrm{d}}\end{array}$ & $5(23.8)$ & $12(57.1)$ & $\begin{array}{l}7(16.3) \\
0.226^{\mathrm{d}}\end{array}$ & $3(3.33)$ & $4(4.44)$ & $\begin{array}{l}2(7.16) \\
0.651^{\mathrm{d}}\end{array}$ & $2(7.16)$ & $8(7.66)$ \\
\hline
\end{tabular}

${ }^{\mathrm{a}} \mathrm{mgr}$, ${ }^{\mathrm{b}}$ systolic/diastolic, ${ }^{\mathrm{c}}$ borderline $=$ systolic $\leq 140$ and diastolic $>90$, systolic $>140$ and diastolic $\leq 90$, and ${ }^{\mathrm{d}} P$ value derived from chi-squared test.

dietary recommendations when preparing food (unhealthy eating behavior) had significant correlation with patient's occupation (unemployed) $(\mathrm{OR}=4.05,95 \% \mathrm{CI}=1.04-15.78$, $(P=0.044)$ ), and blood pressure level (systolic/diastolic $\geq 140$ / 90) $(\mathrm{OR}=2.76,95 \% \mathrm{CI}=1.28-5.96,(P=0.010))$. The behavior of adding salt more than the recommended amount at the table correlated with sex (men) $(\mathrm{OR}=4.47,95 \% \mathrm{CI}=1.21-16.57$, $(P=0.025))$, age $(54-59) \quad(\mathrm{OR}=0.05,95 \% \mathrm{CI}=0.01-0.39$, $(P=0.005))$, and knowledge (general) $(\mathrm{OR}=1.06,95 \%$ $\mathrm{CI}=0.99-1.13,(P=0.05))$ was also a predictor of high dietary salt intake among other predictors (Table 6).

\section{Discussion}

Hypertensive patients showed significant differences in behavioral patterns in salt taking. The differences related to sex, occupation, and blood pressure levels of the patients. About half of the patients, men and women, added optimal amount of salt (not at all or only $1 \mathrm{tsp}$ salt) when preparing food, and more than half of the patients added only 1 tsp salt during eating or at the table.

The predictors that determine the amount of extra salt intake both during preparing and eating food are occupation (unemployed), uncontrolled blood pressure, sex (men), age (54-59), and also patient knowledge (general). It means unemployed patients and those with high blood pressure; systolic/diastolyic $\geq 140 / 90$ add extra amount of salt while preparing food, and usually men and patient older than 54 years add extra salt at the table. In addition, the general knowledge of the patients about the customary amount of salt for hypertensive conditions, salty foods, and the 
Table 3: Patients' knowledge, attitude, and behavior.

\begin{tabular}{|c|c|c|c|c|}
\hline & $\begin{array}{c}\text { All } \\
N=205\end{array}$ & $\begin{array}{c}\text { Women } \\
129(62.9)\end{array}$ & $\begin{array}{c}\text { Men } \\
76(37.1)\end{array}$ & $P$ \\
\hline Knowledge (general) & & & & $0.995^{\mathrm{a}}$ \\
\hline $\mathrm{M}(\mathrm{SD})^{\mathrm{e}}$ & $13.42(5.69)$ & $13.43(5.26)$ & $13.42(6.40)$ & \\
\hline Knowledge on disease related to high-salt intake & & & & $0.999^{\mathrm{b}}$ \\
\hline Correct answer ${ }^{\mathrm{C}}$ & $200(97.6)$ & $126(97.7)$ & $74(97.4)$ & \\
\hline Attitude & & & & $0.023^{\mathrm{a}}$ \\
\hline $\mathrm{M}(\mathrm{SD})^{\mathrm{e}}$ & $16.17(3.74)$ & $16.63(3.38)$ & $15.40(4.19)$ & \\
\hline Behavior & & & & $0.243^{\mathrm{b}}$ \\
\hline \multicolumn{5}{|l|}{ Adding salt during cooking food } \\
\hline No or less than 1 tsp $^{\mathrm{f}}$ & $92(44.9)$ & $55(42.6)$ & $37(48.7)$ & \\
\hline Over 1 tsp $^{f}$ & $131(55.1)$ & $74(57.4)$ & $39(51.3)$ & \\
\hline Adding salt during eating & & & & $<0.001^{\mathrm{b}}$ \\
\hline No or less than $1 \mathrm{tsp}^{\mathrm{f}}$ & $122(59.5)$ & $91(70.5)$ & $31(40.8)$ & \\
\hline Over $1 \mathrm{tsp}^{\mathrm{f}}$ & $83(40.5)$ & $38(29.5)$ & $45(59.2)$ & \\
\hline
\end{tabular}

${ }^{\mathrm{a}} P$ value derived from independent $t$-test, ${ }^{\mathrm{b}} P$ value derived from chi-squared test and Fishers' exact test, ${ }^{\mathrm{c}} \mathrm{N}(\%)$ presented. ${ }^{\mathrm{e}} \mathrm{Mean}$ (standard deviation), and $\mathrm{g}_{\text {one teaspoon. }}$

TABle 4: Patient knowledge on disease related to high-salt intake based on blood pressure level.

\begin{tabular}{|c|c|c|c|c|c|}
\hline & $\begin{array}{c}\text { Blood pressure level } \\
<140 / 90^{\mathrm{a}}\end{array}$ & Borderline $^{\mathrm{b}}$ & $\geq 140 / 90^{\mathrm{a}}$ & All & $P^{\mathrm{d}}$ \\
\hline $\begin{array}{l}\text { Patient knowledge on disease related to high-salt intake } \\
\text { Correct answer }\end{array}$ & $138(97.0)$ & $42(97.0)$ & $20(95.0)$ & $20(98.0)$ & 0.001 \\
\hline
\end{tabular}

TABLE 5: Patient knowledge on the recommended salt intake for healthy and unhealthy people.

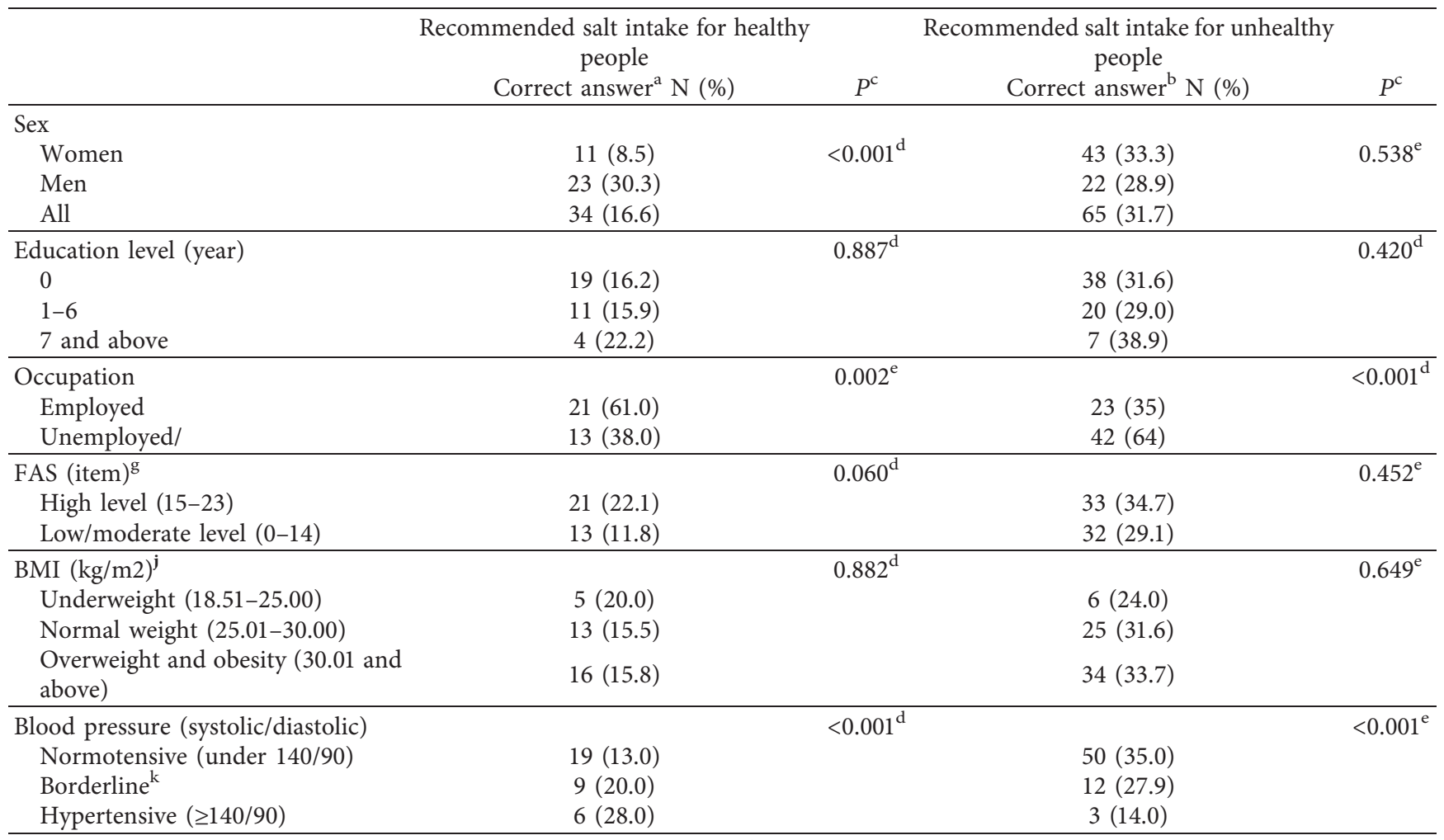

${ }^{\mathrm{a}}$ Patient's knowledge about recommended optimal salt intake for healthy people, ${ }^{\mathrm{b}}$ patient's knowledge about recommended optimal salt intake for unhealthy people, and ${ }^{\mathrm{c}, \mathrm{d}, \mathrm{e}} \mathrm{P}$ value derived from chi-squared test and Fishers' exact test. ${ }^{\mathrm{g}}$ Family Affluence Scale, ${ }^{\mathrm{j}}$ body mass index, and ${ }^{\mathrm{k}}$ borderline: cystolic $\leq 140$ and diastolic $>90$, systolic $>140$ and diastolic $\leq 90$. 
TABLE 6: Results of logistic regression analysis for adding salt during cooking and eating food $\left(0=1\right.$ tsp $^{\mathrm{a}}$ or less and $1=$ more than 1 tsp $\left.\mathrm{p}^{\mathrm{a}}\right)$.

\begin{tabular}{|c|c|c|c|c|}
\hline & Adjusted OR 95\% (CI $)^{\mathrm{b}}$ & $P^{\mathrm{c}}$ & Adjusted OR 95\% (CI) ${ }^{\mathrm{b}}$ & $P^{\mathrm{c}}$ \\
\hline \multicolumn{5}{|l|}{ Sex } \\
\hline Women & Ref.(1) ${ }^{\mathrm{d}}$ & & Ref.(1) ${ }^{\mathrm{d}}$ & \\
\hline Men & $0.46(0.12-1.79)$ & 0.262 & $4.47(1.21-16.57)$ & 0.025 \\
\hline \multicolumn{5}{|l|}{ Age (year) } \\
\hline Under 33 & Ref.(1) ${ }^{\mathrm{d}}$ & & Ref. $(1)^{\mathrm{d}}$ & \\
\hline $34-43$ & $0.29(0.04-3.10$ & 0.304 & $0.22(0.03-1.88)$ & 0.167 \\
\hline $44-53$ & $0.13(0.02-1.21)$ & 0.074 & $0.17(0.03-1.18)$ & 0.074 \\
\hline $54-59$ & $0.22(0.02-2.49)$ & 0.205 & $0.05(0.01-.3 .93)$ & 0.005 \\
\hline 60 and above & $0.21(0.02-1.91)$ & 0.165 & $0.22(0.03-1.54)$ & 0.127 \\
\hline Education level (year) & $1.04(0.59-1.82)$ & 0.902 & $0.87(0.47-1.63)$ & 0.673 \\
\hline \multicolumn{5}{|l|}{ Occupation } \\
\hline Employed & Ref. $(1)^{\mathrm{d}}$ & & Ref. $(1)^{\mathrm{d}}$ & \\
\hline Unemployed & $4.05(1.04-15.78)$ & 0.044 & $1.10(0.26-3.50)$ & 0.954 \\
\hline \multicolumn{5}{|l|}{ FAS (item)e } \\
\hline High level (15-23) & Ref.(1) ${ }^{\mathrm{d}}$ & & Ref. $(1)^{\mathrm{d}}$ & \\
\hline Low/moderate level (0-14) & $1.10(0.54-1.83)$ & 0.987 & $1.32(0.69-2.54)$ & 0.398 \\
\hline \multicolumn{5}{|l|}{$\operatorname{BMI}(\mathrm{kg} / \mathrm{m} 2)^{\mathrm{f}}$} \\
\hline BMI (normal weight) & Ref.(1) ${ }^{\mathrm{d}}$ & & Ref. $(1)^{\mathrm{d}}$ & \\
\hline BMI (overweight) & $1.57(0.57-4.32)$ & 0.383 & $.678(0.23-1.91)$ & 0.479 \\
\hline BMI (obese) & $1.51(0.54-4.24)$ & 0.435 & $1.01(0.51-2.15)$ & 0.897 \\
\hline \multicolumn{5}{|c|}{ Blood pressure (systolic/diastolic) } \\
\hline Normotensive & Ref.(1) ${ }^{\mathrm{d}}$ & & Ref.(1) ${ }^{\mathrm{d}}$ & \\
\hline Hypertensive $(\geq 140 / 90)$ & $2.76(1.28-5.96)$ & 0.010 & $1.02(0.41-2.11)$ & 0.839 \\
\hline Knowledge (general) & $1.04(0.98-1.10)$ & 0.227 & $1.06(0.99-1.13)$ & 0.051 \\
\hline Attitude & $1.02(0.94-1.12)$ & 0.884 & $1.08(0.99-1.18)$ & 0.105 \\
\hline
\end{tabular}

${ }^{\mathrm{a}}$ One teaspoon, ${ }^{\mathrm{b}}$ odds ratio $95 \%$ (confidence interval) for adding salt more than one teaspoon during food preparation, ${ }^{\mathrm{b}}$ odds ratio $95 \%$ (confidence interval) for adding salt more than one teaspoon during eating (adjusted for age, sex, occupation, FAS, BMI, blood pressure levels, knowledge, and attitude), ${ }^{\mathrm{c}} \mathrm{P}$ value derived from logistic regression method, ${ }^{\mathrm{d}}$ reference group, ${ }^{\mathrm{e}}$ Family Affluence Scale, and fbody mass index.

association of salt with related complications play a significant role in salt intake.

Considering the specific knowledge of patients about the amount of salt intake for healthy people and related disease (hypertension), this study indicated that this amount differed significantly by sex. Yet, the patient knowledge about connection between hypertension and high-salt intake was significantly influenced by hypertensive levels of the patients rather than sex. Actually, patient knowledge on salt intake allowance for hypertensive people was not significant based on sex; instead, it differed significantly by patient blood pressure levels and occupation. It seemed hypertensive patients got knowledge about salt intake allowances because of their own health problem rather than their educational levels, socioeconomic status, and BMI. While according to the WHO studies low socioeconomic status can be a factor inducing hypertension [1], this study did not find it as an influential factor.

The results of this study came into agreement with Johnson et al. [20] in that, there was no significant correlation between knowledge and behavior of patients according to their education levels. However, coming into conflict with the results of Qin et al. [35], our findings showed that in general, hypertensive patients, no matter men and women, did not have enough knowledge about connections between hypertension and excessive salt intake. The significant specific knowledge difference related to blood pressure levels of the patients. Actually, patients became aware of the connection between too much salt intake and hypertension after becoming hypertensive. On the other hand, Sanchez et al. studied [36] knowledge and behaviors related to salt intake in urban and rural regions of three countries: Argentina, Costa Rica, and Ecuador. The results showed that the participants had a general knowledge about the amount of salt intake, that is, the risks were perceived, but the study subjects did not find themselves at risk at all, and in turn, they did not read food labels and had no tendency to learn about the salt and sodium content of processed and ready-to-eat foods [36].

Similar to the studies of Corne'lio et al. and Grime et al. $[6,19]$, our findings showed that there were different predictive variables about behavior of adding salt when preparing food and during eating foods. The behavior of adding salt when preparing food (more than one teaspoon) was more prevalent among women, especially unemployed women. This is because in most communities, it is usually women who prepare food. As it is evident in our study, $58 \%$ of the women were responsible for preparing food. By contrast, adding salt at the table (shaking habit) was more common among men. Another study showed that adding salt when preparing food was most prevalent among Japanese hypertensive patients. This was most likely attributed to high consumption of soy sauce and also the traditional ways of preparing food [37].

Adding salt at the table is particularly prevalent among illiterate, 54-59-years-old Iranian rural men. The percentage of men (59.2\%) who added salt at the table was about twice as much as the women (25.9) and significant. Indeed, adding 
salt in preparing food or at the table can have habitual and psychologically unconscious reasons [6]. Women get satisfied while preparing food at the kitchen, and men get satisfied by adding salt to the food which was already saltadded [6]. The adverse behavior of adding more than one teaspoon salt when preparing food was significant based on occupation (unemployed) and blood pressure levels of patients, and during eating food or at the table based on sex (men), age (54-59), and the general knowledge of the patients.

Regarding the importance of knowledge about the recommended amounts of salt intake and its effects on behavioral patterns of healthy and hypertensive people, it is crucial to design and implement educational programs to develop healthy dietary behavior and to control blood pressure targeting both women and men hypertensive patients based on their blood pressure levels and general knowledge.

4.1. Limitations. Both men and women were taken as the sample of the study. The sample size was small because inclusion criteria was limited to the newly diagnosed (the last six months) hypertensive patients, and data analysis was not significant in some areas such as socioeconomic status.

\section{Conclusion}

The different behavioral patterns of salt intake was observed between men and women according to knowledge and occupation (unemployed) and age of the patients about the right amount of salt intake. In general, the amount of salt taken by men and women hypertensive patients is higher than recommended allowances. Both men and women add extra amount of salt to food, women in preparing food, and men at the table.

Salt intake level both during preparing and eating food may be associated with occupation (unemployed), blood pressure level (systolic/diastolic $\geq 140 / 90$ ), sex (men), age (54-59), and also patient knowledge (general).

It is essential to provide both separate and shared educational programs for men and women to meet their different educational needs. In separate sessions, women should be educated not to add extra salt in preparing food, and men should be educated not to add salt at the table. The shared educational sessions should be held for men and women who live together to ask them to make their choice. That is, whether they want salt be added to food in preparation time or at the table. It is also beneficial to suggest them to use homemade spices instead of salt in their food. Meanwhile, the amount of salt in processed and preprepared foods should be monitored continuously to make necessary plans to prevent food factories adding excessive amount of salt to food.

\section{Data Availability}

All raw data used for providing support the findings of this study are availble at the end of this article in the supplementary information file.

\section{Conflicts of Interest}

The authors declare that they have no conflicts of interest.

\section{Acknowledgments}

This is an original study which was taken from a postgraduate thesis supported by Tabriz University of Medical Sciences (no. P/326/Oct. 2016). Our appreciation goes to the participants who patiently answered our questions to fill out the questionnaires and provided us with samples to do the necessary laboratory investigations. We also thank the health officials and personnel for their precious assistance. This research was funded by the Research and Technology Deputy of Tabriz University of Medical Sciences (no: 5/D/ 69686, 2 Oct. 2016).

\section{Supplementary Materials}

Additional file1: all raw data set (Data set.xls). (Supplementary Materials)

\section{References}

[1] World Health Organization (WHO), Global Status Report on Non-communicable Diseases 2014: Attaining the Nine Global Non-communicable Diseases Targets; a Shared Responsibility, World Health Organization (WHO), Geneva, Switzerland, 2014, http://www.who.int/about/licensing/copyright_form/ en/index.html.

[2] O. M. N. Khatib and M. S. El-Guindy, Clinical Guidelines for the Management of Hypertension, World Health Organization, Regional Office for the Eastern Mediterranean, Geneva, Switzerland, 2005, http://www.who.int/iris/handle/10665/ 119738.

[3] World Health Organization (WHO), Global Health Risks: Mortality and Burden of Disease Attributable to Selected Major Risks, World Health Organization (WHO), Geneva, Switzerland, 2009, http://www.who.int/evidence/bod.

[4] I. J. Brown, I. Tzoulaki, V. Candeias, and P. Elliott, "Salt intakes around the world: implications for public health," International Journal of Epidemiology, vol. 38, no. 3, pp. 791-813, 2009.

[5] U. A. Ajani, S. B. Dunbar, E. S. Ford, A. H. Mokdad, and G. A. Mensah, "Sodium intake among people with normal and high blood pressure," American Journal of Preventive Medicine, vol. 29, no. 5, pp. 63-67, 2005.

[6] M. E. Corne'lio, M. C. B. J. Gallani, G. Godin, R. CM. Rodrigues, W. Nadruz Jr., and R. D. R. Mendez, "Behavioural determinants of salt consumption among hypertensive individuals," Journal of Human Nutrition Diet, vol. 25, no. 4, pp. 334-344, 2012.

[7] World Health Organization (WHO), Global Action Plan for the Prevention and Control of Non-communicable Diseases 2013-2020, World Health Organization (WHO), Geneva, Switzerland, 2013, http://www.who.int/nmh/events/ncd_ action_plan/en.

[8] Iranian National Committee for NCDs Prevention and Control (INCDC), National Action Plan for the Prevention and Control of non-Communicable Diseases and Related Risk Factors in the Islamic Republic of Iran, 2015-2025, vol. 14p. 22, 2015, https://ncdrc.info. 
[9] M. R. Joffres, N. R. C. Campbell, B. Manns, and K. Tu, "Estimate of the benefits of a population-based reduction in dietary sodium additives on hypertension and its related health care costs in Canada," Canadian Journal of Cardiology, vol. 23, no. 6, pp. 437-443, 2007.

[10] N. R. Cook, J. A. Cutler, E. Obarzanek et al., "Long term effects of dietary sodium reduction on cardiovascular disease outcomes: observational follow-up of the trials of hypertension prevention (TOHP)," British Medical JournaL, vol. 334, no. 7599, p. $885,2007$.

[11] F. J. He and G. A. MacGregor, "A comprehensive review on salt and health and current experience of worldwide salt reduction programmes," Journal of Human Hypertension, vol. 23, no. 6, pp. 363-384, 2009.

[12] L. J. Appel, C. M. Champagne, D. W. Harsha et al., "Effects of comprehensive lifestyle modification on blood pressure control: main results of the PREMIER clinical trial," Journal of the American Medical Association, vol. 289, no. 16, pp. 2083-2093, 2003.

[13] N. J. Aburto, S. Hanson, H. Gutierrez et al., "Effect of increased potassium intake on cardiovascular risk factors and disease: systematic review and meta-analyses," British Medical Journal, vol. 346, no. 3, p. f1378, 2013.

[14] F. J. He, S. Pombo-Rodrigues, and G. A. MacGregor, "Salt reduction in England from 2003 to 2011: its relationship to blood pressure, stroke and ischaemic heart disease mortality," BMJ Open, vol. 4, no. 4, Article ID e004549, 2014.

[15] S. Yusuf, S. Hawken, S. Ônpuu et al., "Effect of potentially modifiable risk factors associated with myocardial infarction in 52 countries (the INTERHEART study): case-control study," The Lancet, vol. 364, no. 9438, pp. 937-952, 2014.

[16] J. Zhang, A.-Q. Xu, J.-X. Ma et al., "Dietary sodium intake: knowledge, attitudes and practices in Shandong province, China, 2011," PLoS One, vol. 8, no. 3, Article ID e58973, 2013.

[17] K. Bibbins-Domingo, G. M. Chertow, P. G. Coxson et al., "Projected effect of dietary salt reductions on future cardiovascular disease," New England Journal of Medicine, vol. 362, no. 7, pp. 590-599, 2010.

[18] C. A. M. Anderson, L. J. Appel, N. Okuda et al., "Dietary sources of sodium in China, Japan, the United Kingdom, and the United States, women and men aged 40 to 59 years: the INTERMAP Study," Journal of the American Dietetic Association, vol. 110, no. 5, pp. 736-745, 2010.

[19] C. A. Grime, L. J. Riddlle, and C. A. Nowson, "The use of table and cooking salt in a sample of Australian adults," Asian Pacific Journal of Clinical Nutrition, vol. 19, no. 2, pp. 256260, 2010.

[20] C. Johnson, S. Mohan, K. Rogers et al., "The association of knowledge and behaviours related to salt with 24-h urinary salt excretion in a population from north and south India," Nutrients, vol. 9, no. 2, p. 144, 2017.

[21] M. Rafaei, M. Boshtam, N. Sarraf-Zadegan, and S. Seira, "The relation between salt Intake and blood pressure among Iranians," Kuwait Medical Journal, vol. 40, pp. 191-195, 2008.

[22] F. Azizi, M. Rahmani, S. Allahverdian, and M. Hedayati, "Effects of salted food consumption on urinary iodine and thyroid function tests in two provinces in the Islamic Republic of Iran," East Mediterean Health Journal, vol. 7, pp. 115-120, 2001.

[23] S. Fahimi and P. Pharoah, "Reducing salt intake in Iran: priorities and challenges," Archives of Iranian Medicine, vol. 15, no. 2, pp. 110-112, 2012.

[24] National High Blood Pressure Education Program (NHBPE), The Seventh Report of the Joint National Committee on Prevention, detection, Evaluation and Treatment of High Blood
Pressure, U.S. department of Health and Human Services, National Institutes of Health, National Heart, Lung, and Blood Institute; NIH Publication, Bethesda, MD, USA, 2004, https://www.nhlbi.nih.gov/files/docs/guidelines/jnc7full.pdf.

[25] US Department of Agriculture and US Department of Health and Human Services, Dietary Guidelines for Americans, U.S. Government Printing Office, Washington, DC, USA, 2010, https://health.gov/dietaryguidelines/dga2010/, 7th edition.

[26] World Health Organization (WHO), Reducing Salt Intake in populations.Report of a WHO Forum and Technical Meeting 2006, WHO, Geneva, Switzerland, 2014, http://www.who.int/ dietphysicalactivity/Salt_Report_VC_april07.pdf.

[27] A. Kamran, L. Azadbakht, G. Sharifirad, B. Mahaki, and A. Sharghi, "Sodium intake, dietary knowledge, and illness perceptions of controlled and uncontrolled rural hypertensive patients," International Journal of Hypertension, vol. 2014, Article ID 245480, 7 pages, 2014.

[28] B. Shokrvash, L. Salehi, M. Hariri Akbari et al., "Social support and dairy products intake among adolescents: a study from Iran," BMC Public Health, vol. 15, no. 1, p. 1078, 2015.

[29] M.-A. Land, J. Webster, A. Christoforou et al., "The association of knowledge, attitudes and behaviours related to salt with 24-hour urinary sodium excretion," International Journal of Behavioral Nutrition and Physical Activity, vol. 11, no. 1, p. 47, 2014.

[30] World Health Organization and Pan American Health Organization Regional (WHO/PAHO), "Regional Expert Group for cardiovascular disease prevention through populationwide dietary salt reduction (sub-group for research and surveillance) protocol for population level sodium determination in 24-hour urine samples," 2010, http://www.paho.org/ hq/index.php?option=comMay2010.

[31] D. Aune, A. Sen, M. Prasad et al., "BMI and all cause mortality: systematic review and non-linear dose-response metaanalysis of 230 cohort studies with 3.74 million deaths among 30.3 million participants," British Medical Journal, vol. 353, p. i2156, 2016.

[32] F. H. Esfahani, G. Asghari, P. Mirmiran, and F. Azizi, "Reproducibility and relative validity of food group intake in a food frequency questionnaire developed for the Tehran Lipid and Glucose Study," Journal of Epidemiology, vol. 20, no. 2, pp. 150-158, 2010.

[33] A. F. Malekshah, M. Kimiagar, M. Saadatian-Elahi et al., "Validity and reliability of a new food frequency questionnaire compared to $24 \mathrm{~h}$ recalls and biochemical measurements: pilot phase of Golestan cohort study of esophageal cancer," European Journal of Clinical Nutrition, vol. 60, no. 8, pp. 971977, 2006.

[34] World Health Organization (WHO), Guideline: Sodium Intake for Adults and Children, World Health Organization (WHO), Geneva, Switzerland, 2012, http://www.who.int.

[35] Y. Qin, T. Li, P. Lou et al., "Salt intake, knowledge of salt intake, and blood pressure control in Chinese hypertensive patients," Journal of the American Society of Hypertension, vol. 8, no. 12, pp. 909-914, 2014.

[36] G. Sánchez, L. Peña, S. Varea et al., "Knowledge, perceptions, and behavior related to salt consumption, health, and nutritional labeling in Argentina, Costa Rica, and Ecuador," Pan American Journal of Public Health, vol. 32, no. 4, pp. 259-264, 2012.

[37] T. Hashimoto, F. Yagami, M. Owada, T. Sugawara, and M. Kawamura, "Salt preference according to a questionnaire vs. Dietary salt intake estimated by a spot urine method in participants at a health check-up center," Internal Medicine, vol. 47, no. 5, pp. 399-403, 2008. 